\title{
A formação docente de professores de cursos de bacharelado: desafios da prática pedagógica
}

\section{The teaching training of teachers of bachelor courses: challenges of pedagogical practice}

\author{
La formación docente de profesores de cursos de \\ bacharelado: desafíos de la práctica pedagógica
}

Altair Alberto Fávero
(iD) $h t t p: / / o r c i d . o r g / 0000-0002-9187-7283$
Evandro Consaltér
(iD) $h t t p: / / o r c i d . o r g / 0000-0002-9187-7283$
Carla Cristine Tramontina
(iD $h t t p: / / o r c i d . o r g / 0000-0002-9187-7283$

Resumo: O presente estudo tem como objetivo analisar como professores de cursos superiores de bacharelado podem qualificar o processo de ensino/aprendizagem através da aquisição de conhecimentos didáticos e pedagógicos. Para tal, fazemos uso de pesquisa cunho qualitativo, que desenvolve-se a partir da triangulação de dados bibliográficos e empíricos. O método analítico é utilizado para estabelecer o olhar crítico e reflexivo sobre os dados apurados. Assim, primeiramente, fazemos uma construção teórico-bibliográfica acerca da construção da identidade docente. Em seguida, destacamos a importância dos docentes incorporarem à sua prática não apenas conhecimentos específicos de sua área, mas também saberes didáticos e pedagógicos. Por fim, através das respostas de um questionário aplicado via Google Forms, analisamos as potencialidades e as dificuldades enfrentadas por professores dos cursos de Administração, Ciências Contábeis e Economia de uma universidade localizada no norte do Rio Grande do Sul/Brasil. Esses profissionais, em sua grande maioria, não tiveram na sua formação inicial e nem na pós-graduação disciplinas relacionadas à didática e à prática pedagógica. Concluindo, apontamos alguns caminhos para que, através da formação continuada, seja possível contemplar as necessidades de professores que, assim como a grande maioria dos pesquisados, em sua formação inicial não foram preparados para o exercício da docência.

Palavras-chave: Docência. Identidade docente. Saberes pedagógicos.

Abstract: The present study aims to analyze how teachers of bachelor's courses in higher education can qualify the teaching / learning process through the acquisition of didactic and pedagogical knowledge. To do this, we make use of qualitative research, which develops from the triangulation of bibliographical and empirical 
data. The analytical method is used to establish a critical and reflexive look at the data. Thus, first, we make a theoretical-bibliographic construction about the construction of the teaching identity. Next, we highlight the importance of teachers incorporating into their practice not only specific knowledge of their area, but also didactic and pedagogical knowledge. Finally, through the answers of a questionnaire applied through Google Forms, we analyzed the potentialities and difficulties faced by professors of the courses of Administration, Accounting and Economics of an university located in the north of Rio Grande do Sul / Brazil. These professionals, for the most part, did not have in their initial and postgraduate training courses related to didactics and pedagogical practice. Finally, we point out some ways so that, through continuing education, it is possible to contemplate the needs of teachers who, like the vast majority of those surveyed, in their initial formation were not prepared for teaching.

Keywords: Teaching. Teaching identity. Pedagogical knowledge.

Resumen: El presente estudio tiene como objetivo analizar como profesores de cursos superiores de bachillerato pueden calificar el proceso de enseñanza / aprendizaje a través de la adquisición de conocimientos didácticos y pedagógicos. Para ello, hacemos uso de investigación cuño cualitativo, que se desarrolla a partir de la triangulación de datos bibliográficos y empíricos. El método analítico se utiliza para establecer la mirada crítica y reflexiva sobre los datos obtenidos. Así, primero, hacemos una construcción teórico-bibliográfica acerca de la construcción de la identidad docente. A continuación, destacamos la importancia de los docentes incorporar a su práctica no sólo conocimientos específicos de su área, sino también saberes didácticos y pedagógicos. Por último, a través de las respuestas de un cuestionario aplicado a través de Google Forms, analizamos las potencialidades y las dificultades enfrentadas por profesores de los cursos de Administración, Ciencias Contables y Economía de una universidad ubicada en el norte de Rio Grande do Sul / Brasil. Estos profesionales, en su gran mayoría, no tuvieron en su formación inicial y ni en el postgrado disciplinas relacionadas a la didáctica ya la práctica pedagógica. Concluyendo, apuntamos algunos caminos para que, a través de la formación continuada, sea posible contemplar las necesidades de profesores que, así como la gran mayoría de los encuestados, en su formación inicial no fueron preparados para el ejercicio de la docencia. Palabras clave: Enseñanza. Identidad docente. Saberes pedagógicos.

\section{Introdução}

A profissão docente sempre foi considerada a "profissão do conhecimento". Para o professor da Universidade de Sevilla, Carlos Marcelo García, o conhecimento, o saber, é o elemento legitimador da profissão docente e a justificação do trabalho do professor temse baseado no compromisso de transformar esse conhecimento em aprendizagens relevantes para os alunos (MARCELO GARCÍA, 2009). Todavia, para que isso se efetive, é necessário que se estabeleça um consistente processo de ensino e aprendizagem. Diante desse imperativo, o primeiro grande desafio que se coloca à profissão docente é responder a seguinte pergunta: como se aprende a ensinar?

Essa pergunta se torna ainda mais desafiadora para professores que não tiveram em sua formação inicial e nem na pós-graduação disciplinas relacionadas à didática e à prática pedagógica. Esse é o caso comum de muitos docentes de cursos superiores de bacharelado, por exemplo. Geralmente, são profissionais que se destacam em suas áreas e que, por meio de concursos, processos simplificados ou até mesmo convites, acabam assumindo 
o posto de professores na graduação, na pós-graduação ou em cursos de curta duração, como técnico-profissionalizantes. O principal desafio que se coloca a esses profissionais é, na sua atividade docente, deixarem de se enxergar como administradores, contadores ou economistas, por exemplo, e se vislumbrarem como professores de administração, de ciências contábeis e de economia.

Conforme Junges e Behrens (2015, p. 288), "na universidade, os professores que possuem uma atividade profissional liberal e estão inseridos no mercado de trabalho, atuando na área específica na qual lecionam e dedicam-se parcial e paralelamente à docência, são valorizados por sua competência e êxito nessa profissão como administradores, arquitetos, entre outros." Por sua vez, os professores universitários que, conforme bem destacam Junges e Behrens (2015, p. 288), "se dedicam inteiramente à docência, a carreira acadêmica, geralmente, é valorizada e enaltecida muito mais pelas publicações que realiza do que por seu desempenho em sala de aula." Diante destas duas situações apresentadas pelas autoras, a competência pedagógica fica em segundo plano.

Junges e Behrens (2015) consideram que a dualidade deste cenário de ação docente no Ensino Superior permite e possibilita algumas importantes constatações que implicam diretamente na forma de como esse profissional desempenha sua função em sala de aula. Para as autoras, o docente universitário despende maior dedicação e tempo de estudo às atividades de pesquisa do que às atividades inerentes ao ensino, incluindo sua formação na área pedagógica. Dessa forma, consideram comum professores universitários "se identificarem socialmente, mais no campo científico (como advogados, arquitetos, médicos etc.), do que como docentes (como professor de)" (JUNGES; BEHRENS, 2015, p.288). Essa identificação profissional explicaria o motivo pelo qual "as atividades acadêmicas que realizam (os livros que leem; os cursos/ eventos que frequentam; os artigos que produzem) estão mais relacionadas à sua formação inicial como profissionais bacharéis e liberais do que com a docência propriamente dita” (JUNGES; BEHRENS, 2015, p.288).

Diante deste cenário e partindo do questionamento de "como se aprende a ensinar", propomos, neste estudo, analisar a construção da identidade docente de professores que atuam em cursos superiores de bacharelado. Em especial, analisamos as potencialidades e as dificuldades relacionadas à prática pedagógica dos docentes dos cursos de Administração, Ciências Contábeis e Economia da maior Universidade do norte Gaúcho (Rio Grande do Sul/Brasil). A pesquisa configura-se de cunho qualitativo e desenvolve-se a partir da triangulação de dados bibliográficos e empíricos. O método analítico é utilizado para estabelecer o olhar crítico e reflexivo sobre os dados apurados. Para tal, inicialmente abordamos o processo de construção da identidade docente, seus elementos e percurso constitutivo. Em seguida, tomamos como objeto discursivo a necessidade dos docentes incorporarem à sua prática não apenas conhecimentos específicos de sua área, mas também saberes pedagógicos. Por fim, analisamos a experiência dos professores pesquisados, relatadas através de um questionário aplicado pelo Google Forms, sobre seus percursos formativos e 
suas experiências profissionais relacionadas à docência. Nosso referencial apoia-se, principalmente nos estudos de Marcelo García (2009), Pimenta (2008) e Benincá (2002).

A partir do desdobramento proposto, o conjunto deste estudo, em suas análises, conclusões e apontamentos, oferece algumas contribuições para que bacharéis-docentes encontrem alternativas para superarem as lacunas pedagógicas que afetam suas práticas. Também aponta caminhos para que a formação continuada possa suprir as necessidades didáticas e pedagógicas de professores que em sua formação inicial ou pós-graduação não foram preparados para o exercício da docência. Finalmente, esperamos que essa discussão possa contribuir para a qualificação dos processos de ensino/aprendizagem e para melhorar a interação em sala de aula entre docentes e discentes de Ensino Superior.

\section{A construção da identidade docente de professores do Ensino Superior}

A habilitação para a docência no Ensino Superior está prevista na Lei de Diretrizes e Bases da Educação Nacional (LDB), Lei n 9.394, de 20 de dezembro de 1996. Em seu art. 66, a lei determina que "[...] a preparação para o exercício do magistério superior far-se-á em nível de pós-graduação, prioritariamente em programas de mestrado e doutorado" (BRASIL, 1996, p. 22). A LDB, através do seu artigo 52 (BRASIL, 1996), também prevê que o corpo docente das universidades deve ter de pelo menos um terço de seus professores com titulação acadêmica de mestrado ou doutorado. Todavia, estudos como o de Barros e Dias (2016) revelam que essa "preparação" para a docência na Educação Superior revela-se insuficiente para dar conta da importância da formação pedagógica e dos desafios que se colocam à profissão docente.

Dessa forma, é muito comum que os processos seletivos de admissão de professores para o Ensino Superior contemplem mais os conhecimentos específicos do professor em relação a sua área de formação do que os conhecimentos pedagógicos para o exercício da docência. O fato é que a essência da pós-graduação strictu sensu está muito mais voltada para a formação do pesquisador do que para a formação do professor de Ensino Superior, conforme apontado por Barros e Dias (2016). Esse perfil do pós-graduado é ainda mais latente quando se fala de cursos strictu sensu ligados à mesma área de formação inicial, como, por exemplo, bacharéis em administração, ciências contábeis ou encomia. Em seu percurso formativo, esses cursos não costumam apresentar disciplinas voltadas para a formação pedagógica.

Nesta perspectiva de que a pós-graduação seria responsável pela formação do professor universitário, Fávero e Pasinato (2013, p. 204) ressaltam que "nem sempre o bom pesquisador é um bom professor. São inúmeras as situações em que 'pesquisadores de excelência' têm dificuldades de ministrar boas aulas, não conseguem estabelecer relações pedagógicas que promovam a aprendizagem dos alunos, não possuem habilidades didáticas para 'traduzir' suas pesquisas em conteúdos pedagógicos de suas aulas." Fávero e Pa- 
sinato (2013) destacam que tais investigadores, não raramente, não são capazes de realizar uma autocrítica, justificando suas ações em seu status como reconhecidos pesquisadores.

Nesse sentido é importante ressaltar que a formação do professor universitário seja um dos fatores determinantes para que aconteça a qualidade educativa, para que ocorra melhorias no processo ensino-aprendizagem e principalmente na possibilidade da formação de um cidadão consciente e emancipado. Como observam Fávero e Pasinato (2013, p.105), "não se pode atribuir à educação formal toda a responsabilidade da mudança e da transformação social, pois a estrutura social impõe muitas limitações à ação educacional", no entanto, a boa formação pedagógica dos professores universitários pode se tornar um elemento decisivo na formação dos futuros profissional que passam pela educação superior.

Para Behrens (2011), essa situação torna-se ainda mais latente quando professores que atuam na docência universitária são profissionais liberais que nunca fizeram uma formação pedagógica. Muitos se aventuram numa docência de ensaio e erro por anos na tentativa de melhorar sua desenvoltura em sala de aula. Fávero e Tonieto (2015) destacam que na intenção de dar conta da formação pedagógica ausente no processo formativo desses professores, muitos gestores de instituições de Ensino Superior, equivocadamente, acreditam que tal lacuna formativa pode ser sanada oferecendo palestras e cursos estanques no início do ano letivo ou no decorrer do ano. Essas iniciativas, dependendo dos seus palestrantes, em alguns casos podem até surtir alguns efeitos efêmeros, porém, na maioria das vezes, revelam-se eventos enfadonhos, que na concepção dos docentes tem apenas função protocolar.

Diante deste cenário, Behrens (2011) considera que os primeiros passos para superar esta falsa compreensão de docência está em superar três crenças que podem cristalizar a prática da improvisação docente. A primeira delas é desconstruir a ideia de que o docente nasce pronto; a segunda, de que para ser docente basta ser um bom profissional em sua área; a terceira, de que para ensinar basta ter conteúdo. Superar estas três crenças seria o primeiro passo para fazer com que profissionais liberais, ao optarem pela docência no ensino superior, no momento em que entram na sala de aula se reconheçam enquanto professores. O segundo passo, entendemos que seria construir a sua própria identidade docente.

Dessa forma, construir uma identidade alicerçada em consistentes pilares teóricos e epistemológicos permitiria ao docente incorporar a sua atividade saberes didáticos e pedagógicos potencializadores do processo de ensino e aprendizagem. Todavia, quando a o exercício docente pauta-se apenas pelo domínio de conhecimentos específicos de uma determinada área, corre-se o risco de, como apontado por Becker (1993), exercer a atividade docente como um ajuste ou uma adaptação, pautada por uma vivência, por uma experiência de vida ou até mesmo pelo senso comum pedagógico.

Ao se falar em senso comum pedagógico, é importante ressaltar que não se trata de negá-lo, mas sim de contextualizá-lo ao processo educativo. Tanto Boaventura de 
Sousa Santos (1989) como Elli Benincá (2002) apoiam-se na ideia de que o senso comum não deve ser ignorado ou descartado para dar lugar à ciência, mas sim que ele deve ser transformado com base na ciência. Essa transformação, de acordo com Pimenta (2008), pode ocorrer a partir da construção de uma identidade docente mobilizada por três distintos saberes: os saberes da experiência, os saberes do conhecimento e os saberes pedagógicos.

Ao abordar os saberes da experiência, Pimenta (2008) considera que todos os professores, em um determinado período de suas vidas, passaram pela escola como alunos e, dessa forma, guardam lembranças desses tempos em relação aos seus professores, seus colegas e a diferentes escolas. Outros, já tiveram a oportunidade de estarem nas salas de aula como professores em virtude de um magistério ou de um curso técnico que Ihes concedeu a oportunidade de ministrarem determinados conteúdos específicos. Neste caso, o desafio dos cursos de formação inicial e continuada é, portanto, fazer com que esses profissionais construam sua própria identidade docente e superem o olhar sobre a docência, sobre o ser professor e a escola do ponto de vista do ser aluno e passem a vislumbrar do ponto de vista de ser professor.

Por sua vez, os saberes do conhecimento destacados pela autora, fazem referência ao mundo de informações em que estudantes de graduação, em especial aos de licenciatura, são submetidos. São os conhecimentos do conteúdo disciplinar. A dúvida que paira sobre os futuros profissionais é o que e como fazer exatamente com esse conhecimento e como fazer com que esse conhecimento mobilize processos de ensino e aprendizagem eficientes. Geralmente, esses saberes são adquiridos durante a graduação ou em uma especialização, porém também podem ser adquiridos através de estudos individuais, como, por exemplo, na leitura de livros ou artigos científicos.

Por fim, os saberes pedagógicos elencados por Pimenta (2008) revelam a necessidade de os profissionais da educação incorporarem à sua bagagem formativa não apenas conhecimentos específicos, mas também saberes pedagógicos e didáticos. Na história dos cursos de formação de professores, esses saberes têm sido trabalhados de forma isolada e distinta. Na história da educação, sobressaem-se destaques sobre os saberes científicos e saberes técnicos, porém, ao passo que a escola configura-se como uma instituição não estática, assim como mudam as características sociais, o fazer pedagógico também deve ser ponto de análise e reflexão.

A partir da mobilização destes três distintos saberes abordados por Pimenta (2008), os professores reuniriam um conjunto de capacidades técnicas e pedagógicas para orientar a atividade docente de forma qualitativa e propositiva. Deter o conhecimento específico da sua área de atuação é um requisito básico para todo bom professor. Porém, como já bem apontado por Behrens (2011), só isso não basta. Tão importante quanto os saberes específicos são os saberes pedagógicos. Afinal, quem já não ouviu a famosa frase: "aquele professor sabe muito, pena que não sabe ensinar". 


\section{A necessidade de incorporar à prática docente saberes pedagógicos}

O exercício docente tem exigido cada vez mais a incorporação de novos saberes, não comtemplados na formação inicial e, também, por vezes distantes do que se verifica nas instituições de Ensino Superior em termos de formação continuada. Para atender essas novas demandas, o docente necessita de um "saber plural, formado de diversos saberes provenientes das instituições de formação, da formação profissional, dos currículos e da prática cotidiana" (TARDIF, 2005, p. 54). Esse saber plural forneceria os elementos necessários para, como afirma Marcelo García (2009, p. 07), a "construção de um eu profissional, que evolui ao longo das suas carreiras" e vai integrando a construção da identidade docente, conforme Benincá (2002) e Pimenta (2008).

Em outras palavras, esse "saber plural" chamado por Tardif (2005) também poderia ser chamado de saber pedagógico, um saber que correlaciona os conhecimentos técnicos do profissional docente com as habilidades didáticas necessárias para efetivação de consistentes processos de ensino e aprendizagem. Conforme Tardif (2005, p. 61), esses conhecimentos "parecem ser, portanto, plurais, compósitos, heterogêneos, pois trazem à tona, no próprio exercício do trabalho, conhecimentos e manifestações do saber-fazer e do saber ser, bastante diversificados e provenientes de fontes variadas".

Para Marcelo García (2009, p. 08), um eu profissional que evolui ao longo de sua carreia docente é aquele que consegue incorporar à sua prática esse conhecimento plural, conforme o apontado por Tardif (2005), e assumir a responsabilidade e compromisso de "transformar esse conhecimento em aprendizagens relevantes para os alunos" (MARCELO GARCÍA, 2009, p. 08). Nesse sentido, entendemos que a incorporação de saberes pedagógicos à prática docente pode ser processada por diferentes caminhos. A formação inicial é um deles, quando tratamos de cursos de licenciatura. A pós-graduação na área da educação pode e deve ser outro caminho. Sobre este aspecto, num estudo feito por Fávero e Tonieto (2016, p. 41-42) sobre o lugar da teoria na pesquisa sobre docência na educação superior, ressaltam que não se constitui uma formação continuada de qualidade se não estiver ancorada numa construção teórica consistente, pois "é a teoria que nos auxilia a projetar o que fazer, como fazer, para onde ir, onde ter um interesse, o que observar, o que fazer com o percebido". A formação continuada e a formação a partir da práxis pedagógica, como bem disserta Benincá (2002), constituem-se em outra valiosa possibilidade de articular produtivamente formação docente com um consistente processo de teorização sobre a própria formação.

Diante desses caminhos possíveis para se buscar os conhecimentos pedagógicos, concordamos com Tardif (2005, p. 64) quando argumenta que a profissão docente se constitui também da "confluência entre várias fontes de saberes provenientes da história de vida individual, da sociedade, da instituição escolar, dos outros atores educativos, dos lugares de formação [...]". Ou seja, o docente se constitui das relações que estabelece com os de- 
mais sujeitos, com os conhecimentos acadêmicos e com a sua própria experiência de vida e de professor, neste caso, de Ensino Superior.

Dessa forma, a pesquisa sobre a sua própria prática docente também possibilita pontuar ações para aperfeiçoar o trabalho, pois os saberes pedagógicos são fundamentais para direcionar o aprender a aprender junto aos educandos. É ter conhecimentos teóricos/ epistemológicos, mas também sensibilidade, indagação teórica e criatividade para enfrentar as situações incertas e ambíguas do contexto acadêmico. Espera-se que o professor pesquisador seja aquele que "mobilize conhecimentos da teoria da educação e da didática necessários à compreensão do ensino como realidade social, e que desenvolva neles a capacidade de investigar a própria atividade" como destaca Pimenta (1999, p. 18).

Essa postura investigativa da própria prática pedagógica é apontada por Marcelo García (2009) como a grande possibilidade de tornarem-se profissionais capazes de fazer aprendizagens eficientes ao longo da vida. Para isso, o autor julga necessário combinar competência com capacidade de inovação. Essa receita resultaria no conceito de "professor perito", aquele que já acumula certa experiência na docência, mas que tem uma estrutura de conhecimento profunda e de multiníveis, com muitas conexões inter e intra-nível. O professor perito, conforme Marcelo García (2009), utiliza seu conhecimento teórico para, juntamente com suas experiências práticas, criar representações abstratas dos problemas enfrentados na docência e, assim, refletir sobre as melhores soluções.

De acordo com Marcelo García (2009), os professores peritos reconhecem e identificam características de problemas e situações que podem escapar à atenção dos principiantes ou daqueles que simplesmente acumulam anos de docência sem se preocupar em aprimorar suas práticas. O conhecimento do perito é muito mais do que uma lista de informações e fatos desconexos acerca de determinada disciplina. "O seu conhecimento está interrelacionado e organizado em torno de ideias importantes acerca das suas disciplinas" (MARCELO GARCÍA, 2009, p.14). Essa organização de conhecimento ajuda os professores peritos a saberem quando, por que e como utilizar o conhecimento que possuem numa situação concreta. A cada novo desafio, teriam a possibilidade de transformar as suas competências, aprofundálas e ampliálas continuamente ao longo de sua carreira profissional.

Essa característica dos professores peritos favoreceria a transformação da prática pedagógica em um processo contínuo de (re)construção. Para Tardif $(2005$, p. 70) os saberes dos professores "são temporais, pois são utilizados e se desenvolvem no âmbito de uma carreira" e, é esse processo que contribui para transformar a prática. A carreira do professor é "um processo de socialização", sinalizando que os saberes do docente derivam da prática pedagógica e não somente da teoria. O espaço constituído pelo docente na sua prática produz conhecimentos e é campo de pesquisa e investigação para que o mesmo possa rever seus conceitos, teorias e conhecimentos.

Nesse sentido, Marcelo García (2009, p. 11) afirma que o "desenvolvimento profissional como um processo que se vai construindo à medida que os docentes ganham experiência, sabedoria e consciência profissional", ou seja, na medida em que vão tornando-se 
peritos. Através da experiência e da reflexão realizada sobre a prática é que os educadores passam a assumir uma postura diferenciada diante dos conhecimentos a serem trabalhados e da metodologia a ser adotada em sala de aula. Deixarão de serem meros repetidores de práticas já vivenciadas para assumirem uma postura crítica-reflexiva diante do saber.

Assim como Pimenta (2008), para Marcelo García(2009) esse processo também pode ser compreendido como uma forma de construção de uma identidade profissional, ou seja, de uma identidade docente. Esse caminho parece ser uma possibilidade de bacharéis-docentes qualificarem suas práticas e processos de ensinar e de aprender. Nessa mesma direção, em Benincá (2002) tem-se a ideia do método da práxis pedagógica como sendo uma forma de autoformação, um processo permanente na vida do professor, que lhe possibilitará ter as condições necessárias para se manter sempre atualizado, sempre em formação.

Dessa forma, entendemos que o professor universitário, principalmente quando falamos de profissionais liberais que entram para a docência ou, em outros termos, bacharéis-docentes, necessita conceber usa formação docente para além dos conhecimentos da área de sua formação inicial e da mera experiência profissional. Conforme Marcelo García (2009) não é totalmente seguro que a simples experiência faça o melhor mestre. Ter uma longa experiência como administrador em diversas empresas não implica necessariamente que o profissional da administração seja, automaticamente, um bom professor. Dizer que a experiência profissional é requisito suficiente para ser um bom profissional docente pode se tornar uma premissa falsa. Resgatando Behrens (2011), isso pode fazer com que professores se aventurem numa docência de ensaio e erro por muitos anos na tentativa de melhorar sua desenvoltura em sala de aula. A experiência e o reconhecimento enquanto profissionais liberais, por si só, não garantem uma prática pedagógica reflexiva, formativa e de qualidade.

Saber ensinar não significa apenas ter domínio de conteúdos ou títulos acadêmicos, mas sim, saber emitir juízos de valor, ser reflexivo, participativo e atuante no contexto em que se insere. Assim como todo professor, é preciso que o bacharel-docente seja alguém comprometido com sua autoformação e que possa discutir com seus pares a prática a fim de ir incorporado elementos pedagógicos indispensáveis para uma prática significativa. É importante frisar que a responsabilidade da formação pedagógica dos docentes não deve ser somente desejo individual, mas que seja parte integrante do processo institucional, pois os saberes pedagógicos são imprescindíveis para o bom exercício docente.

\section{A experiência de bacharéis-docentes de uma universidade do Rio Grande do Sul}

Para qualificar nossa discussão e agregar ao estudo bibliográfico elementos empíricos, realizamos uma pesquisa com professores de Ensino Superior com graduação em bacharelado. Por conta de sua formação em Pós-Graduação, muitos se tonaram docentes e saíram de seus departamentos técnicos para entrar na sala de aula de uma universidade. Diante das reflexões teóricas já expostas, ancoradas principalmente por Marcelo García (2009), Pimenta (2008) e Benincá (2002), na sequência deste estudo, identificaremos al- 
gumas das potencialidades e dificuldades desses professores em lidar com a docência e apontaremos alguns caminhos que possam qualificar as suas atividades docentes.

Dessa forma, elaboramos um questionário eletrônico (Google forms) com 07 questões (5 de múltipla escolha e 2 de respostas discursivas) acerca da atividade docente e da formação pedagógica do professor e o aplicamos aos 95 professores que integram o quadro docente dos cursos de Administração, Ciências Contábeis e Economia, da maior universidade do norte do Rio Grande do Sul. O questionário foi enviado aos professores via e-mail, através da secretaria da unidade acadêmica que abriga os referidos cursos. Foi estipulado um prazo de uma semana para os docentes responderem (de 03 a 10 de dezembro de 2018). Ao final do prazo, obtivemos 26 respondentes, o que equivale a $27 \%$ do total de convites enviados.

A figura abaixo mostra como o questionário foi apresentado aos docentes.

Figura 01 - Apresentação do questionário aos docentes envolvidos na pesquisa

\section{Pesquisa - $A$ atividade docente nos cursos de Administração, Ciências Contábeis e Economia}

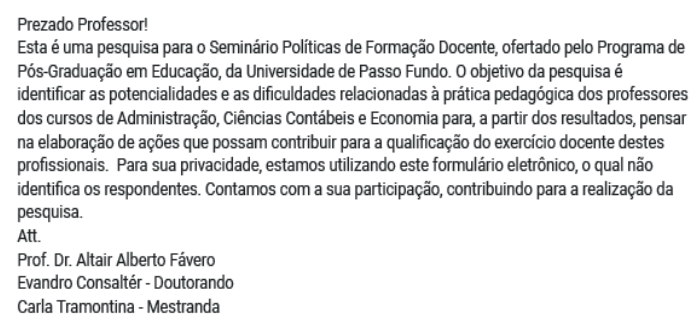

Fonte: elaborada pelos autores.

A primeira pergunta que fizemos aos professores indagou sobre o tempo que já atuam na docência no Ensino Superior. O Gráfico 01 apresenta as respostas.

Gráfico 01 - Sobre o tempo de atuação na docência do Ensino Superior

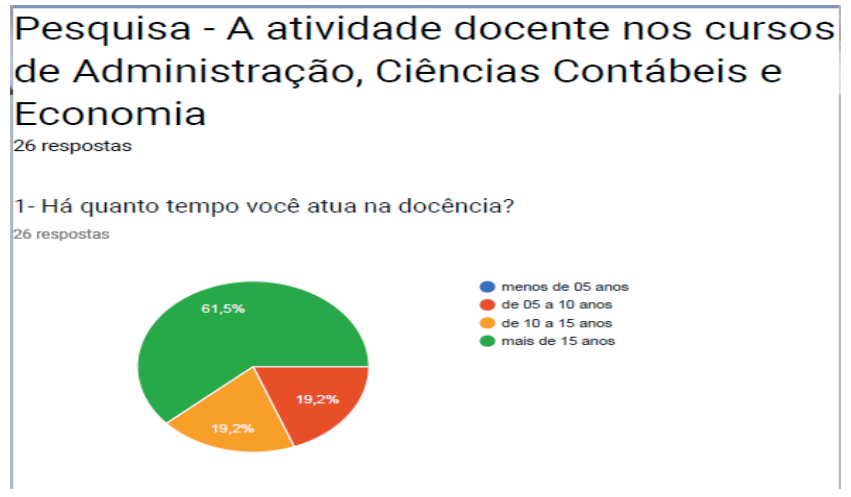

Fonte: elaborada pelos autores. 
Dos 26 respondentes, a grande maioria $(61,5 \%)$ atua na docência no Ensino Superior há mais de 15 anos. Acumulam considerável experiência e já acompanharam a formação acadêmica de diferentes gerações. Os demais respondentes, todos atuam na docência há mais de 5 anos. Outra importante informação é que dos 26 professores, nenhum tem menos de 5 anos de atuação no Ensino Superior. Considerando o "desenvolvimento profissional como um processo que se vai construindo à medida que os docentes ganham experiência, sabedoria e consciência profissional" (MARCELO GARCÍA, 2009, p. 11), podemos afirmar que o quadro docente pesquisado é experiente e apresenta condições para que, aliado à consciência profissional, boas práticas de ensino e aprendizagem possam ser evidenciadas.

Na sequência do questionário, os docentes foram indagados sobre sua formação inicial, ou seja, sobre o curso em que foram graduados. Considerando atuarem em cursos de Administração, Ciências Contábeis e Economia, esperava-se encontrar como principal matriz de formação inicial do corpo docente estes cursos, o que acabou se comprovando nas respostas dos professores. Os resultados são apresentados no Gráfico 02.

Gráfico 02 - Sobre a formação inicial dos professores

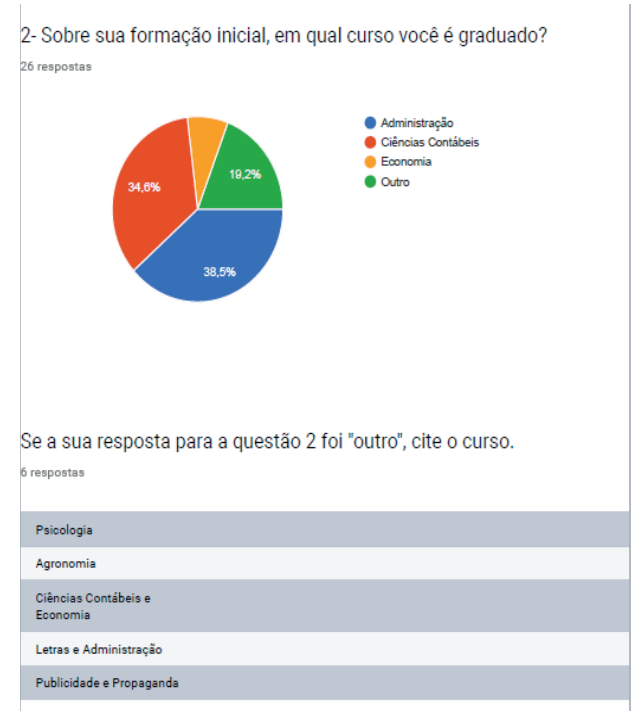

Fonte: elaborada pelos autores.

Administração, Ciências contábeis e Economia, naturalmente, são os cursos que mais estampam a formação inicial dos professores participantes da pesquisa. Dos 26 respondentes, apenas 3 possuem graduação em outros cursos: 1 em Psicologia, 1 em Agronomia, 1 em Publicidade e Propaganda. Outros dois possuem duas graduações cada: 1 em Ciências Contábeis e também em Economia e 1 em Letras e em Administração.

A sequência de nossa investigação junto ao corpo docente atentou para a formação que os professores têm em nível de Pós-Graduação. Considerando que para atuar no 
Ensino Superior, conforme previsto na LDB, através do seu artigo 52 (BRASIL, 1996), o corpo docente das universidades devem ter de pelo menos um terço de seus professores com titulação acadêmica de mestrado ou doutorado. Apesar de possuírem uma parcela significativa de docentes apenas com especialização, essa exigência e bem atendida pela universidade na realidade dos cursos ora analisados. 0 Gráfico 03 estampa essa realidade.

Gráfico 03 - Sobre a formação na Pós-Graduação

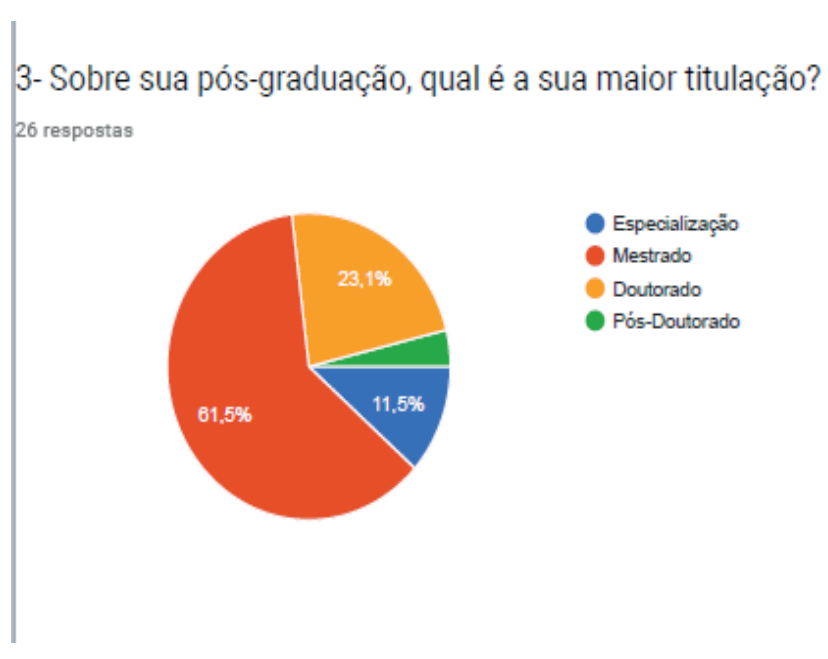

Fonte: elaborada pelos autores.

No entanto, ao analisarmos os dados apresentados através do Gráfico 03, percebemos um número pouco expressivo de professores com pós-doutorado e até mesmo com doutorado. Dos 26 respondentes, apenas 6 têm doutorado e somente 2 pós-doutorado. A Grande maioria dos professores possui mestrado (61,5\%). Ainda, uma parcela significativa, equivalendo $11,5 \%$ dos docentes, possui somente especialização. Apesar de um corpo docente experiente, o fato de existir poucos doutores e pós-doutores atuando nesses cursos pode estar vinculado ao fato de a unidade acadêmica, a qual possui mais de 60 anos, somente ter implantado seu programa de pós-graduação em 2015, com o Mestrado Acadêmico em Administração, o qual recebeu conceito 3 da CAPES no quadriênio em vigência.

Conforme a LDB, assim como um terço do corpo docente deve ser formado por mestres e doutores, a formação em nível de pós-graduação é uma exigência para a atuação no ensino superior. No entanto, deve-se considerar que, conforme já exposto através de Fávero e Pasinato (2013, p. 204), "nem sempre o bom pesquisador é um bom professor". A acumulação de títulos não garante a qualidade dos processos de ensino e aprendizagem. Por isso a necessidade da formação pedagógica, que, neste caso, está muito mais vinculada às práticas de formação continuada dos professores em serviço do que às formações acadêmicas em nível de mestrado ou de doutorado. 
O gráfico 04 nos ajuda a compreender essa realidade, ou seja, de como a formação em Pós-Graduação, por si só, não é suficiente para dar conta dos conhecimentos e habilidades didáticas e pedagógicas necessárias ao docente de Ensino Superior.

\section{Gráfico 04 - Sobre a formação pedagógica}

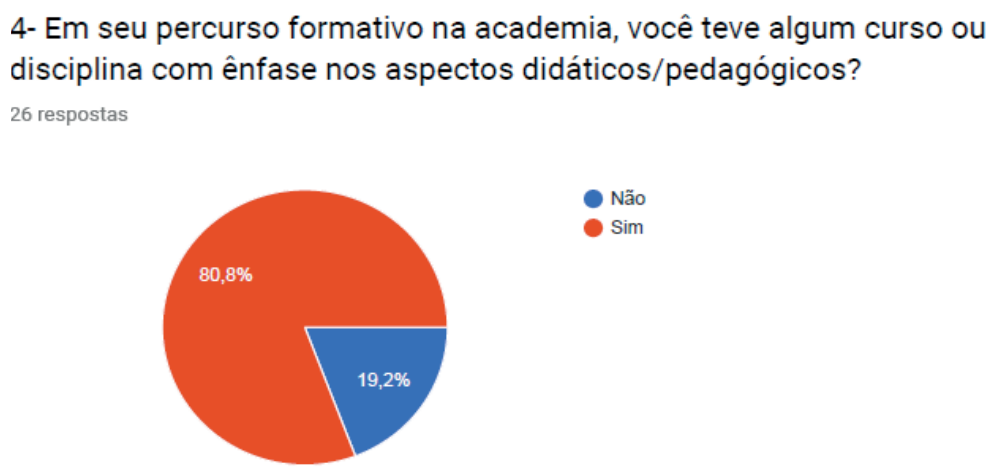

Fonte: elaborada pelos autores.

Dos $80 \%$ dos respondentes que afirmaram terem cursado alguma disciplina com ênfase nos aspectos didáticos/pedagógicos, $30 \%$ deles citam a disciplina de Metodologia do Ensino Superior, cursada durante o curso de mestrado ou no doutorado. Os demais docentes citam cursos de curta duração, como "Iniciação à Docência", "Orientação Educacional" e ainda "Estágio de Docência". Os resultados mostram que, em virtude da formação técnica dos cursos de bacharel, os únicos momentos em que esses professores tiveram algum tipo de contato com aspectos didáticos e pedagógicos foi durante a Pós-Graduação. Porém, conforme já destacamos através dos estudos de Barros e Dias (2016), esses raros momentos são insuficientes para dar conta da importância da formação pedagógica e os desafios se apresentam constantemente diante do professor de Ensino Superior.

Em face deste cenário, mais uma vez fica evidente a importância que a formação continuada representa para a qualificação da prática docente, principalmente de professores como os pesquisados, provenientes de áreas mais técnicas e com bacharelado. Há de se considerar também e reconhecer o empenho desses professores em buscarem uma formação voltada mais para os aspectos didáticos e pedagógicos. Essa iniciativa fica estampada no índice dos $30 \%$ dos docentes que cursaram a disciplina de Metodologia do Ensino Superior, uma disciplina optativa, que é ofertada no Programa de Pós-Graduação em Educação - PPGEdu da Universidade. Na opinião dos docentes pesquisados, essa disciplina contribuiu de forma significativa para enfrentarem as dificuldades encontradas na docência, dificuldades estas estampadas na sequência, através da Figura 02. 
Figura 02 - Sobre as dificuldades enfrentadas pelos professores

\author{
5- Qual é a maior diculdade que você já enfrentou ou enfrenta na \\ docência? \\ 26 respostas
}

Novas metodologias de ensino e aprendizagem que utilizem a tecnologia disponivel, bem como tem ?exibilidade para atender a constante mudança dos alunos. Ao mesmo tempo, que permitam atender um

aluno que chega do ensino médio, quase que um analfabeto funcional.

O crescente desinteresse e falta de preparo dos alunos

A falta de interesse dos alunos.

Inovação no ensino

Utilizar novas metodologias de ensino em disciplinas especi?cas

Interesse dos discentes

diferentes disciplinas em cada semestre.

Agora, é difícil lembrar a maior di?culdade. Uma di?culdade é prender a atenção dos alunos, é fazer com que eles participem. Também relacionado a isso, sinto di?culdade em competir com o celular que cada um traz. Acho que deviamos fazer uma grande mudança no currículo de Administração, nas disciplinas e na forma que as aulas são desenvolvidas, para torná-las mais interessantes aos alunos. Gosto muito de levar eles até o Laboratório de Informática e realizar atividades de pesquisa sobre um determinado assunto relacionado à disciplina. Observo que, na maioria das vezes, eles gostam de fazer isso e se envolvem.

Não ter resposta para todos os questionamentos.

Falta de infraestrutura tecnológica e di?culdade de internet

Motivar o jovem atual a interessar-se a estudar, qualquer que seja disciplina ou conteúdo.

O desa?o de sempre inovar as práticas pedagógicas de modo a despertar a atenção dos alunos.

Adequação e adoção de novas metologias em sala de aula.

A falta de conh cimentos básicos do aluno (ensino médio). Melhorou nos últimos anos mas ainda e a maior di?culdade.

Divergências em relação ao nivel de exigência da avaliação, que na percepção do aluno era muito alto.

Os alunos chegam com di?culdades em termos de leitura, interpretação, comunicação escrita e oral, bem como de atitudes relativas aos hábitos de estudo.

projetar o aluno na carreira escolhida

incrementar e acrescentar tecnologias práticas nas atividades

Lidar com a diversidade geracional em sala de aula e tempo disponivel para elaborar uma aula, com exercícios didáticos que instigam o aluno a participar. Atrair e envolver alunos no contexto atual é uma das maiores di?culdades, cujas anteriores citadas tornam-se consequência.

A necessidade de inovar nas práticas pedagógicas sem termos infraestrutura

A pouca valorização da pro?ssão mediante a própria comunidade acadêmica; O comportamento dos acadêmicos, muitas vezes presenciei a relação de clientelismo de forma prejudicial a minha atuação.

A maior di?culdade enfrentada na docência é o per?! das novas gerações de acadêmicos.

Elaboração de atividades que preencham os quatro períodos de aula.

Falta de interesse dos alunos

Tornar as aulas mais práticas e atrativas

Avaliação

Fonte: elaborada pelos autores. 
A ausência de uma formação pedagógica na carreira desses professores pode ter um reflexo nas respostas para este questionamento. As dificuldades mais citadas pelos docentes dizem respeito à dificuldade de prender a atenção dos alunos e ao desinteresse dos mesmos em relação ao exposto em aula. Outro aspecto de grande preocupação entre os docentes refere-se às dificuldades de articularem suas aulas com as novas tecnologias e a necessidade que sentem de incorporarem novas metodologias de ensino.

Se somarmos as respostas "prender a atenção dos alunos" e "desinteresse dos alunos", as mais citadas entre os docentes, chegamos a um expressivo número que corresponde a quase $40 \%$ das principais dificuldades dos professores pesquisados. Os dados revelam uma preocupação que não diz respeito a problemas técnicos ou de caráter de domínio teórico, mas sim de implicações didáticas e pedagógicas. Reforçam a tese defendida por Marcelo García (2009) de que não é totalmente seguro que a simples experiência faça o melhor mestre. Dá mesma forma, conforme Fávero e Pasinato (2013), que nem sempre o bom desempenho de um pesquisador resultará em um bom desempenho enquanto professor.

Os dados ora apurados reforçam a premissa de Benincá (2002) de que a formação continuada e a formação a partir da práxis pedagógica constituem-se em valiosas possibilidades de superar ou melhor enfrentar essas dificuldades. É justamente sobre esta temática, formação continuada, que aborda o Gráfico 05.

Gráfico 05 - Sobre a formação continuada na universidade

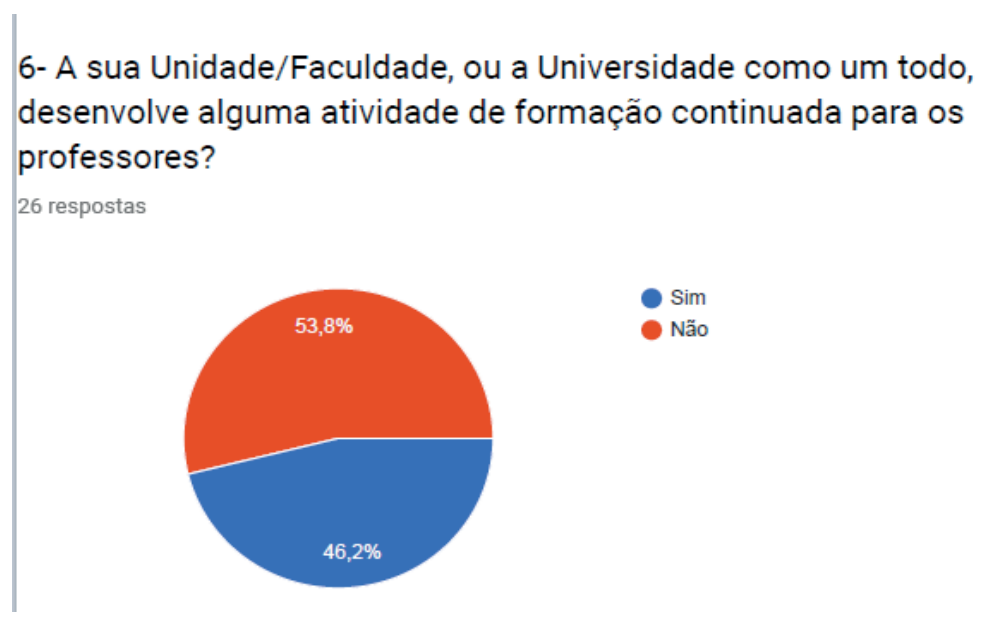

Fonte: elaborada pelos autores.

Segundo os professores, a atividade que mais tem contribuído para o aprimoramento de suas práticas em sala de aula é o programa de formação docente oferecido pela universidade no período de recesso. Denominado de Curso de Qualificação Docente, a atividade foi adotada pela universidade em 2016 e integra o Programa de Formação Docente já institucionalizado e coordenado pela Vice-Reitoria de Graduação, juntamente com o Setor de Apoio de Pedagógico. O curso tem o propósito de oportunizar um momento de 
aprimoramento e qualificação para os professores da instituição. Em sua página eletrônica, a instituição destaca os seguintes aspectos como principais objetivos do evento formativo:

a) Qualificar a ação docente na instituição;

b) Promover discussões e intercâmbio de diálogos nas diferentes realidades vivenciadas pelos docentes da instituição;

c) Aprimorar a prática docente nas diferentes áreas do conhecimento, motivando os professores à educação continuada e consequente qualificação profissional;

d) Propiciar aos educadores das diferentes áreas do saber, discussões e reflexões sobre a prática docente e sobre inovações metodológicas nas práticas de sala de aula;

e) Integrar, promover o diálogo e motivar os educadores à formação continuada, permitindo um olhar mais qualificado aos processos de ensino;

f) Favorecer a possibilidade de refletir sobre a formação integral que necessariamente implica no ensino, pesquisa e extensão;

g) Oportunizar um espaço de valorização de vivências, experiências e boas ações docentes por meio de oficinas.

Mesmo sendo um evento que acontece em período específico, com duração de cerca de quatro dias, através dos relatos dos docentes, as atividades vivenciadas parecem mobilizar ações e práticas que se estendem durante o ano letivo, principalmente através do diálogo e troca com os pares e da reflexão sobre sua própria prática. Tanto Benincá (2002) quanto Marcelo García (2009) entendem que a capacidade de refletir criticamente sobre sua própria prática pedagógica constitui-se em uma grande possibilidade de apropriar-se do método da práxis pedagógica. Uma vez que o professor se inserir neste processo permanente de autoformação, desfrutaria das condições necessárias para enfrentar os desafios da docência, se manter sempre atualizado e, ao mesmo tempo, sempre em formação. Além disso, favoreceria a construção de uma consistente identidade docente, conforme Pimenta (2008) e Marcelo García (2009).

Quando indagamos os professores sobre ações e temáticas de formação continuada que poderiam contribuir para a qualificação de seu exercício docente, mais uma vez as dificuldades apresentadas na Figura 02 influenciam as demandas dos professores. A Figura 03 estampa as sugestões apresentadas pelos professores. 
Figura 03 - Sobre temáticas sugeridas pelos professores

\section{7- Que ações ou temáticas de formação continuada poderiam contribuir para quali?car a sua atividade docente? \\ 26 respostas}

Metodologias de ensino e aprendizagem que utilizem a tecnologia disponivel e que permitam atender a constante mudança comportamental dos alunos.

Acompanhamento Psicopedagógico

Eu gostava bastante dos cursos que foram ofertados nas férias, as temáticas eram interessantes e a metodologia prática.

Nova formar de ensino e aprendizagem

Metodologias Ativas; Professor da Geração X e Alunos da Geração Y e Z; Aspectos comportamentais, entre outros temas que não os técnicos.

Treinamento sobre Excel

Metodologias novas envolvendo o uso de mídia digital.

Novas técnicas e métodos de ensino; métodos novos que estão sendo utilizados e estão dando certo em outras universidades

Cursos de didática e oratória.

uso de ferramentas tecnológicas

Andragogia (ou Heutagogia)

Formação em ferramentas inovadoras de ensino como EAD, inserção no meio empresarial.

Formação pedagógica, capacitação para uso de novas tecnologias

Dinâmicas de aula.

Inserção de práticas metodológicas aliadas a tecnologia.

Atualização contínua em metodologia de ensino, desa?os que enfrentamos com relação aos alunos que recebemos com carências na formação básica.

novas tecnologias

Aulas interativas - metodologias ativas -

Fonte: elaborada pelos autores.

A maioria dos respondentes acredita que atividades de formação continuada sobre novas metodologias de ensino e sobre metodologias ativas poderiam contribuir significativamente para a qualificação do processo de ensino e aprendizagem. Essa crença ou preocupação dos professores revela um entendimento de que os problemas da docência poderiam ser resolvidos com a aplicação de alguma técnica de ensino. A ideia de formação é reduzida ao uso de uma metodologia que pode ser incorporada e transmitida mecanica- 
mente. No entanto, não existem técnicas, fórmulas ou qualquer tipo de solução pronta para lidar com os desafios que se colocam diante do professor de Ensino Superior.

Resgatando as reflexões de José Manuel Esteve (2004), entendemos que um dos maiores desafios de alguns desses professores, profissionais liberais, é o de superar o olhar para a docência do ponto de vista do administrador, do contador e do economista e passar a concebê-la do ponto de vista do professor de administração, de ciências contábeis e de economia. Os resultados também reforçam a importância de cursos de formação docente como o ofertado pela universidade. Retratam a importância de incorporar à bagagem profissional saberes didáticos e pedagógicos, como defendido por Marcelo García (2009) e também apontado por Fávero e Pasinato (2013) quando defendem a ideia de que uma dos caminhos mais promissores para que aconteça um processo formativo de qualidade é tornar o professor universitário um profissional pesquisador da própria prática docente.

Esses elementos ajudariam esses professores a construírem a sua própria identidade docente e, conforme Pimenta (2008), a afastarem de si a crença de que a solução para os problemas enfrentados na docência está somente em aspectos externos ao exercício do professor, como é o caso da busca por novos macetes e novas metodologias. Para Fávero e Tonieto (2010, p. 69), "se o professor não der continuidade ao seu próprio processo de formação continuada, ele ficará sempre na dependência de cursos externos, visto que é sempre necessário que alguém lhe diga o que fazer e como fazer". Nesse sentido, reforçamos a tese de que a busca por formação externa sem transformação interna não dá conta da complexidade da formação continuada e da construção de uma identidade docente, conforme apresentado.

\section{Considerações finais}

Diante da pergunta desencadeadora desta investigação - como se aprende a ensinar? - após a análise do referencial teórico/bibliográfico e dos dados empíricos, tecemos cinco considerações com o ousado propósito de dar conta, ao menos em parte, do nosso questionamento e de não correr o risco de praticar o que condenamos no texto, ou seja, proferir aqui um receituário, uma prescrição.

I. Não existe receita pronta para os problemas da docência. Aprender a ensinar não significa adotar a postura do professor como "técnico", o qual sempre recorre aos especialistas e estudiosos em educação para obter uma resposta quanto "ao que deve ser feito" e "a como deve ser feito" quando diante de uma situação nova. A sua função, como bem destacado por Fávero e Tonieto (2010), restringira-se apenas a de aplicar os procedimentos considerados eficazes, sempre pensados e justificados por outros, e não a de dialogar e investigar como os outros. Entendemos que o problema não está nas sugestões, mas sim em como estas são recebidas por esses professores. "Uma vez que a ação pedagógica é reduzida a uma situação instrumental controlada, qualquer contingência é suficiente 
para deixar o professor sem saber o que fazer ou que atitude tomar, pois a técnica não é eficaz por si mesma; ela conta, na verdade, com a capacidade humana de criação" (FÁVERO; TONIETO, 2010, p. 60).

II. A ação deve partir do próprio docente. O conceito de desenvolvimento profissional adotado por Marcelo (2009) sugere a combinação de competência com capacidade de inovação. Essa combinação, conforme analisamos, resultaria no conceito de profissional perito, neste caso professor perito. Com uma estrutura de conhecimento profunda e de multiníveis, com muitas conexões inter e intra-nível, o professor perito utiliza seu conhecimento teórico para, juntamente com suas experiências práticas, criar representações abstratas dos problemas enfrentados na docência e, assim, refletir sobre as melhores soluções. Conforme Nóvoa (2009) é relevante que a formação de professores passe para "dentro da formação", isto é, ser conduzida e planejada pelos próprios professores. Na tese de Benincá (2002), reuniria as condições para desenvolver uma formação a partir da práxis pedagógica, com o exercício reflexivo de sua prática, caracterizado pela autoformação e formação coletiva, que compreende um processo metodológico de observação da prática, por sua vez registrada e refletida de forma sistemática. Esse exercício configura-se como possibilidade de compreender, assimilar e buscar a superação dos desafios contemporâneos da docência.

III. Experiência não garante desempenho. Acumular anos de experiência sem desenvolver a capacidade de inovação não contribui para a qualificação das práticas docentes. Nesse sentido, conforme já destacamos, Marcelo García (2009) afirma que o desenvolvimento profissional eficiente é aquele que vai se construindo na medida em que os docentes ganham experiência, mas também sabedoria e consciência profissional. É através dessa combinação que os professores reúnem condições necessárias para assumir uma postura diferenciada diante dos conhecimentos a serem trabalhados e da metodologia a ser adotada em sala de aula para a qualificação do processo de ensino e aprendizagem. Assim, os docentes deixarão de serem meros repetidores de práticas já vivenciadas para assumirem uma postura crítica-reflexiva diante do saber. Como ressaltam Fávero e Tonieto (2010, p.48), "nesse modelo de formação de professores reflexivos, a prática adquire o papel central de todo o currículo, pois se torna, ao mesmo tempo, o lugar da aprendizagem e o espaço de construção do pensamento prático do professor".

IV. Titulação não garante qualidade de ensino. Conforme já destacado neste estudo, Fávero e Pasinato (2013, p. 204) consideram que "nem sempre o bom pesquisador é um bom professor". A falta de conhecimentos pedagógicos e de habilidades didáticas para traduzir suas pesquisas em conteúdos de suas aulas faz com que se crie um distanciamento entre quem ensina e quem aprende. Quando se projeta que titulação é sinônimo de qualidade, se produz uma falsa ilusão que 
basta titular os professores para termos qualidade educativa. Tendo em vista que a pós-graduação strictu sensu está muito mais voltada para a formação do pesquisador do que para a formação do professor de Ensino Superior, torna-se urgente organizar processos formativos que possam qualificar a docência nos seus múltiplos aspectos. Mesmo que a LDB determine que a preparação para o exercício do magistério superior far-se-á em nível de pós-graduação, prioritariamente em programas de mestrado e doutorado, a incorporação de saberes didáticos e pedagógicos, essenciais para o bom desempenho docente, está muito mais sob responsabilidade da formação continuada e da sua práxis pedagógica, do que em títulos acadêmicos. Os dados empíricos analisados neste estudo revelam a importância desta modalidade formativa, uma vez que os professores pesquisados explicitam a formação continuada como uma das melhores possibilidades que veem para qualificar suas práticas pedagógicas.

V. Cada professor deve construir sua identidade docente. Em se tratando de bacharéis-docentes, torna-se ainda mais importante a construção desta identidade. Usamos a terminologia "construção" justamente porque entendemos que a identidade docente é algo que se constrói ao longo da carreira. A identidade docente não é algo pronto que se adquire de imediato quando se entra na sala de aula contratado por uma instituição para ministrar uma determinada disciplina. Nos tornamos docentes ao longo do percurso, ao exercer profissionalmente a docência. De acordo com Pimenta (2008), essa construção ocorre a partir da mobilização dos saberes da experiência, dos saberes do conhecimento e dos saberes pedagógicos.

Dessa forma, como já analisamos, a aquisição de saberes didáticos e pedagógicos é fundamental para que os professores de Ensino Superior, em especial neste caso que investigamos, em analogia ao apontado por Esteve (2004), possam superar o olhar para a docência do ponto de vista do administrador, do contador e do economista e passar a concebê-la do ponto de vista do professor de administração, de ciências contábeis e de economia. Essa postura evitaria que o exercício docente fosse pautado apenas pelo domínio de conhecimentos específicos de uma determinada área, correndo-se o risco de, como apontado por Becker (1993), exercer a atividade docente como um simples ajuste ou uma adaptação, aventurando-se, conforme Behrens (2011), numa docência de ensaio e erro por anos na tentativa de melhorar sua desenvoltura em sala de aula. Mas para isso é necessário estar aberto à ideia de construção da própria identidade, de dar-se conta que não nascemos professores, mas nos tronamos professores e podemos ser melhores à medida que conseguirmos refletir sobre nossas práticas.

Após as considerações ora apresentadas, enfatizamos a importância da formação continuada como fundamental para a qualificação das práticas pedagógicas. Para tal, consideramos essencial a articulação entre teoria e prática, a partir da análise de situações concretas do cotidiano escolar, a procura de um conhecimento pertinente na reelaboração 
desse conhecimento, traduzindo um processo de inovação (NÓVOA, 2009). Além disso, enquanto um processo também coletivo, considerando a partilha de experiências e práticas exitosas, Nóvoa (2009) destaca que a formação de professores necessita valorizar o trabalho em equipe, pois a reflexão e o trabalho coletivo transformam-se em conhecimento profissional, instigando processos de mudança e práticas concretas de intervenção.

Por fim, concordamos com Junges e Behrens (2015, p.288) quando afirmam que "além do compromisso institucional com a formação pedagógica de seu quadro docente, é importante que os próprios professores percebam os processos formativos como algo que Ihes é importante e que contribui para sua prática pedagógica, e que, por isso, necessitam ser contínuos". Conforme as autoras, para o professor se dedicar a sua formação pedagógica ele não precisa se desligar por completo de suas pesquisas, nem do exercício de uma profissão paralela, quanto for o caso. Ao contrário disso, ele pode e precisa realizar as duas atividades em conjunto, integrando-as e fazendo com que uma complemente a outra. Porém, quando dentro da sala de aula, deve assumir a sua identidade docente, a qual compreende os saberes específicos da área, mas também os conhecimentos pedagógicos, imprescindíveis para realização de boa prática de ensino e aprendizagem. 


\section{REFERÊNCIAS}

BARROS, Conceição de Maria Pinheiro; DIAS, Ana Maria lorio. A formação pedagógica de docentes bacharéis na educação superior: construindo o Estado da Questão. Revista Educação em Questão. Natal, v. 54, n. 40, p. 42-74, jan./abr. 2016.

BECKER, Fernando. A epistemologia do professor: o cotidiano da escola. Petrópolis: Vozes, 1993.

BENINCÁ, Elli. O senso comum pedagógico: práxis e resistência. Dissertação. Porto Alegre: UFRGS, 2002.

BEHRENS, Marilda Aparecida. Docência universitária: formação ou improvisação? In.: Revista Educação. Vol. 36, nº 3. Santa Maria, pp. 441-453, set/dez, 2011.

BRASIL, Lei n 9.394 - Lei de Diretrizes e Bases da Educação Nacional, de 20 de dezembro de 1996.

ESTEVE, José M. A Terceira Revolução Educacional: a educação na sociedade do conhecimento. Trad. Cristina Antunes. São Paulo: Moderna, 2004.

FÁVERO, Altair Alberto. Políticas de Formação Pedagógica: possibilidades de superar o mal-estar docente. In: CENCI, Ângelo Vitório, DALBOSCO, Cláudio Almir, MÜHL, Eldon Henrique, (org.). Sobre Filosofia e Educação: Racionalidade, diversidade e formação pedagógica. Passo Fundo: Ed. Universidade de Passo Fundo, 2009.

FÁVERO, Altair Alberto; PASINATO, Darciel. O docente universitário como profissional pesquisador de sua própria prática. In: Revista Contrapontos - Eletrônica, Vol. 13 - n. 3 - p. 195-206 / set-dez, 2013.

FÁVERO, Altair Alberto; TONIETO, Carina. Educar o Educador: reflexões sobre a formação docente. Campinas: Mercado de Letras, 2010.

FÁVERO, Altair Alberto; TONIETO, Carina. Formação de professores e suas histórias de vida. In: LOPES, A. R. L. et al (orgs.). Formação de professores em diferentes espaços e contextos. Campo Grande: Editora UFMS, 2011, p.163-181.

FÁVERO, Altair Alberto; TONIETO, Carina. Criatividade não é improvisação: Crítica a uma concepção equivocada de docência universitária. In.: FÁVERO, Altair Alberto; TONIETO, Carina; ODY, Leandro Carlos. Docência Universitária: pressupostos teóricos e perspectivas didáticas. Campinas - SP: Mercado de Letras, 2015.

FÁVERO, Altair Alberto; TONIETO, Carina. O lugar da teoria na pesquisa sobre a docência na educação superior. In: FÁVERO, A. A.; TONIETO, C. (orgs.). Epistemologias da Docência Universitária. Curitiba: CRV, 2016, p.31-49.

INEP, Instituto Nacional de Estudos e Pesquisas Educacionais Anísio Teixeira. Censo da Educação Superior: notas estatísticas 2017. Brasília, MEC/INEP, 2018. 
JUNGES, Kelen dos Santos; BEHRENS, Marilda Aparecida. Prática docente no Ensino Superior: a formação pedagógica como mobilizadora de mudança. PERSPECTIVA, Florianópolis, v. 33, n. 1, 285-317, jan./abr. 2015.

LOPES, Carine Winck. Práticas de leituras de professoras na contemporaneidade \& literatura de autoajuda. Dissertação. Porto Alegre: UFRGS, 2012.

MARCELO GARCÍA, Carlos. Desenvolvimento profissional docente: passado e futuro. Sísifo / revista de ciências da educação $\cdot n \cdot{ }^{\circ} 8 \cdot$ jan/abr 2009.

NÓVOA, António. Formação de professores e profissão docente. In: NÓVOA, António. Os professores e sua formação. Lisboa: Instituto de Inovação Educacional, 1992.

NÓVOA, António. Professores: imagens do futuro presente. Lisboa: Educa, 2009.

PIMENTA, Selma G. Formação de professores: identidade e saberes da docência. In: Saberes pedagógicos e atividade docente. Selma Garrido Pimenta (org.) São Paulo: Cortez, 2008.

PIMENTA, Selma G. Docência no ensino superior. São Paulo: Cortez, 2002.

PIMENTA, Selma Garrido; ANASTASIOU, Léa das Graças Camargo. Docência no ensino superior. São Paulo: Cortez, 2005.

SANTOS, Boaventura de Sousa. Introdução a uma ciência pós-moderna. Rio de Janeiro: Graal, 1989.

TARDIF, Maurice. Saberes docentes e formação profissional. Petrópolis: Vozes, 2002. 